Niels Uth · Henrik Sørensen · Kristian Overgaard

Preben K. Pedersen

\title{
Estimation of $\dot{V}_{2 \max }$ from the ratio between $\mathrm{HR}_{\max }$ and $H R_{\text {rest }}$ - the Heart Rate Ratio Method
}

\begin{abstract}
The effects of training and/or ageing upon maximal oxygen uptake $\left(\dot{V} \mathrm{O}_{2 \max }\right)$ and heart rate values at rest $\left(\mathrm{HR}_{\text {rest }}\right)$ and maximal exercise $\left(\mathrm{HR}_{\text {max }}\right)$, respectively, suggest a relationship between $\dot{V} \mathrm{O}_{2 \max }$ and the $\mathrm{HR}_{\max }-$ to- $\mathrm{HR}_{\text {rest }}$ ratio which may be of use for indirect testing of $\dot{V} \mathrm{O}_{2 \max }$. Fick principle calculations supplemented by literature data on maximum-to-rest ratios for stroke volume and the arterio-venous $\mathrm{O}_{2}$ difference suggest that the conversion factor between mass-specific $\dot{V} \mathrm{O}_{2 \max }\left(\mathrm{ml} \cdot \mathrm{min}^{-1} \cdot \mathrm{kg}^{-1}\right)$ and $\mathrm{HR}_{\text {max }} \cdot \mathrm{HR}_{\text {rest }}{ }^{-1}$ is $\sim 15$. In the study we experimentally examined this relationship and evaluated its potential for prediction of $\dot{V} \mathrm{O}_{2 \max }$. $\dot{V} \mathrm{O}_{2 \max }$ was measured in 46 well-trained men (age 2151 years) during a treadmill protocol. A subgroup $(n=10)$ demonstrated that the proportionality factor between $\mathrm{HR}_{\text {max }} \cdot \mathrm{HR}_{\text {rest }}{ }^{-1}$ and mass-specific $\dot{V} \mathrm{O}_{2 \max }$ was $15.3(0.7) \mathrm{ml} \cdot \mathrm{min}^{-1} \cdot \mathrm{kg}^{-1}$. Using this value, $\dot{V} \mathrm{O}_{2 \max }$ in the remaining 36 individuals could be estimated with an SEE of $0.211 \cdot \mathrm{min}^{-1}$ or $2.7 \mathrm{ml} \cdot \mathrm{min}^{-1} \cdot \mathrm{kg}^{-1}(\sim 4.5 \%)$. This compares favourably with other common indirect tests. When replacing measured $\mathrm{HR}_{\max }$ with an age-predicted one, SEE was $0.37 \mathrm{l} \cdot \mathrm{min}^{-1}$ and $4.7 \mathrm{ml} \cdot \mathrm{min}^{-1} \cdot \mathrm{kg}^{-1}$ $(\sim 7.8 \%)$, which is still comparable with other indirect tests. We conclude that the $\mathrm{HR}_{\max }$-to-HR rest ratio may provide a tool for estimation of $\dot{V} \mathrm{O}_{2 \max }$ in well-trained men. The applicability of the test principle in relation to other groups will have to await direct validation. $\dot{V} \mathrm{O}_{2 \max }$ can be estimated indirectly from the measured $\mathrm{HR}_{\max }{ }^{-}$ to-HR $\mathrm{H}_{\text {rest }}$ ratio with an accuracy that compares favour-
\end{abstract}

\footnotetext{
N. Uth $(\bowtie) \cdot H$. Sørensen $\cdot$ K. Overgaard Department of Sport Science, University of Aarhus, Katrinebjergvej 89C, 8200 N Aarhus, Denmark

E-mail: nielsuth@idraet.au.dk Fax: + 45-8942-4894

P. K. Pedersen

Institute of Sports Science and Clinical Biomechanics, University of Southern Denmark, Campusvej 55, 5230 M Odense, Denmark
}

ably with that of other common indirect tests. The results also suggest that the test may be of use for $\dot{V} \mathrm{O}_{2 \max }$ estimation based on resting measurements alone.

Keywords $\mathrm{HR}_{\max }$-to-HR $\mathrm{HR}_{\text {rest }}$ ratio $\cdot$ Maximal heart rate Maximal oxygen uptake $\cdot$ Resting heart rate

\section{Introduction}

The maximal rate of oxygen uptake uptake $\left(\dot{V} \mathrm{O}_{2 \max }\right)$ is an important determinant of cardiorespiratory fitness and aerobic performance (Howley et al. 1995). Direct measurements of oxygen uptake $\left(\dot{V} \mathrm{O}_{2}\right)$ during maximal work provide the most accurate value for this parameter, and measurements are reproducible with a coefficient of variation of about 2-4\% (Howley et al. 1995). Direct measurements of $\dot{V} \mathrm{O}_{2 \max }$ are, however, technically demanding and require access to expensive laboratory equipment and skilled personnel. As a consequence, alternative procedures have been developed in which $\dot{V} \mathrm{O}_{2 \max }$ is estimated from physiological responses during submaximal exercise (e.g. Astrand and Ryhming 1954; Fox 1973) or from physiological responses in combination with performance measures (e.g. Kline et al. 1987).

Training status is a major determinant of $\dot{V} \mathrm{O}_{2 \max }$. It is well documented that $\dot{V} \mathrm{O}_{2 \max }$ increases with training and that inactivity or cessation of training reduces $\dot{V} \mathrm{O}_{2 \max }$ (e.g. Blomqvist and Saltin 1983). Training, likewise, has been shown to lower resting heart rate $\left(\mathrm{HR}_{\text {rest }}\right)$ (Blomqvist and Saltin 1983) whereas detraining is associated with increased $\mathrm{HR}_{\text {rest }}$ (Katona et al. 1982). This suggests that one would expect a negative relationship between $\dot{V} \mathrm{O}_{2 \max }$ and $\mathrm{HR}_{\text {rest }}$. Whether such a relationship is close enough to merit interest in indirect estimation of $\dot{V} \mathrm{O}_{2 \max }$ is uncertain.

Ageing is associated with decrements in both $\dot{V} \mathrm{O}_{2 \max }$ and $\mathrm{HR}_{\max }$ (Tanaka et al. 2001). The effect of ageing would therefore suggest a positive relationship between $\dot{V} \mathrm{O}_{2 \max }$ and $\mathrm{HR}_{\max }$. If we combine the mentioned influences of training, or ageing, upon the $\dot{V} \mathrm{O}_{2 \max }$ and $\mathrm{HR}$ 
response, it appears likely that a positive relationship exists between $V \mathrm{O}_{2 \max }$ and the ratio between $\mathrm{HR}_{\max }$ and $\mathrm{HR}_{\text {rest }}\left(\mathrm{HR}_{\max } \cdot \mathrm{HR}_{\text {rest }}{ }^{-1}\right)$. Calculations based upon the Fick principle and incorporating literature data for maximum-to-rest ratios for $\mathrm{HR}$, stroke volume and arterio-venous $\mathrm{O}_{2}$ difference, respectively (see Appendix), suggest that mass-specific $\dot{V} \mathrm{O}_{2 \max }$ may be estimated by multiplying $\mathrm{HR}_{\text {max }} \cdot \mathrm{HR}_{\text {rest }}{ }^{-1}$ by a factor of about 15.0 . The purpose of the present study was therefore (1) to examine whether this theoretical proportionality factor could be confirmed by experimental data, and (2) to evaluate in a group of well-trained men the limits of agreement (LOA) (Bland and Altman 1986) for prediction of $\dot{V} \mathrm{O}_{2 \max }$ using the experimentally established proportionality factor.

\section{Methods}

\section{Subjects}

Forty-six healthy well-trained, non-smoking men volunteered to participate in the study. The mean (SD) values for age, height, body mass (BM) and $\dot{V} \mathrm{O}_{2 \max }$ were $29.6(7.7)$ years, $182(6.1) \mathrm{cm}, 76.3$ (6.5) $\mathrm{kg}, 4.66(0.49) \mathrm{l} \cdot \mathrm{min}^{-1}$ and $60.9(5.5) \mathrm{ml} \cdot \mathrm{min}^{-1} \cdot \mathrm{kg}^{-1}$, respectively. They trained on average 8.7 (2.9) h per week. All subjects provided written informed consent in accordance with the guidelines of the local Ethics Committee. The experiments complied with the standards of the local Ethics Committee.

\section{Study design}

The subjects were randomly assigned to either of two groups. One group $(n=10)$ validated the proportionality factor between the mass-specific $\dot{V} \mathrm{O}_{2 \max }$ and the $\mathrm{HR}_{\max }$-to- $\mathrm{HR}_{\text {rest }}$ ratio (theoretical value $\sim 15)$. The other group $(n=36)$ was used to establish LOA between $\dot{V} \mathrm{O}_{2 \max }$ estimates based upon the $\mathrm{HR}_{\text {max }}-$ to- $-\mathrm{HR}_{\text {rest }}$ ratio and the above factor, versus direct measurements of $V \mathrm{O}_{2 \max }$.

\section{Experimental protocol}

Height was measured to the nearest $0.5 \mathrm{~cm}$ and $\mathrm{BM}$ determined to the nearest $0.1 \mathrm{~kg}$. Exercise experiments were performed on a motordriven treadmill (Technogym Runrace, Gambettola, Italy). The subjects warmed up for $10 \mathrm{~min}$ at a speed and grade selected to impose a heart rate of $\sim 140$ beats $\mathrm{min}^{-1}$. The typical initial running speed was $13 \mathrm{~km} \cdot \mathrm{h}^{-1}$. Speed (first part of the test) and/or inclination (later part) were subsequently increased stepwise every minute by $1 \mathrm{~km} \cdot \mathrm{h}^{-1}$ or $2 \%$ slope, respectively, to exhaustion. The duration of the test ranged 5-10 min. Pulmonary gas exchange and heart rate were monitored continuously during the test. High-intensity and/or high-volume training was avoided for $48 \mathrm{~h}$ prior to testing. Resting heart rate was measured over a 5 -min period by the subject in the morning the day after the test (supine, while in bed). $\mathrm{HR}_{\text {rest }}$ (beats $\mathrm{min}^{-1}$ with one decimal) was defined as the lowest value of any 1 -min average during the 5-min sampling period. $\mathrm{HR}_{\max }$ was defined as the highest 5-s average during the treadmill test.

\section{Techniques}

Pulmonary gas exchange was measured with an automated metabolic cart system (AMIS 2001, Innovision, Odense, Denmark). Ventilatory flow rate was measured on the inspiratory side with a differential pressure sensor (Pneumotachograph - Lilly type, Innovision $\mathrm{A} / \mathrm{S}$, Odense, Denmark.). $\dot{V} \mathrm{O}_{2 \max }$ was defined as the highest $\dot{V} \mathrm{O}_{2}$ measured during any 30 -s period. Heart rate was measured with a Polar Electro heart rate monitor (Kempele, Finland). A test was approved as being maximal when at least three of the following four criteria were met: (1) a plateau in $\dot{V} \mathrm{O}_{2}$ despite increased running speed or inclination (increase $<150 \mathrm{ml} \cdot \mathrm{min}^{-1}$ ), (2) R-value $\geq 1.15$, (3) ventilatory equivalent for oxygen $>30$, and (4) terminal HR within 10 beats $\mathrm{min}^{-1}$ of age-predicted $\mathrm{HR}_{\max }$. The $\mathrm{HR}_{\max }$ was predicted from age using the formula of Tanaka et al. (2001): $\mathrm{HR}_{\max }($ age-predicted $)=208-0.7 \cdot$ age in years.

\section{Statistics}

Analysis of variance (ANOVA) was performed to analyse differences between group means. Pearson's coefficient of correlation $(r)$ was used to describe the relationship between $\dot{V} \mathrm{O}_{2 \max }$ as well as the mass-specific $\dot{V} \mathrm{O}_{2 \max }$ and selected physiological variables. BlandAltman plots (1986) were employed to establish the LOA between measured and estimated $\dot{V} \mathrm{O}_{2 \max }$. Operationally, LOA define the range within which $95 \%$ of the individual differences between measured and estimated $\dot{V} \mathrm{O}_{2 \max }$ will lie. After calculating the standard error of estimate (SEE) for the differences between measured and estimated $\dot{V} \mathrm{O}_{2 \max }$, a 95\% confidence interval $( \pm 1.96$ SEE) is determined around the mean difference. As part of the analysis, differences between measured and estimated $\dot{V} \mathrm{O}_{2 \max }$ were plotted against their average and tested for homoscedasticity. Statistical significance was set at $P<0.05$ for all analyses.

\section{Results}

The experimentally determined proportionality factor between mass-specific $\dot{V} \mathrm{O}_{2 \max }$ and $\mathrm{HR}_{\max } \cdot \mathrm{HR}_{\text {rest }}{ }^{-1}$ was $15.26(0.72) \mathrm{ml} \cdot \mathrm{min}^{-1} \cdot \mathrm{kg}^{-1}$ which is not significantly different from the theoretical value of $\sim 15 \mathrm{ml} \cdot \mathrm{min}^{-1} \cdot \mathrm{kg}^{-1}$. Highly statistically significant correlations were found between measured $\dot{V} \mathrm{O}_{2 \max }$ and the estimated counterparts using the Heart Rate Ratio Method. Correlation coefficients for $\dot{V} \mathrm{O}_{2 \max }$ in $\mathrm{ml} \cdot \mathrm{min}^{-1}$ averaged 0.91 $\left(P<0.001\right.$; see Fig. 1a) and for mass-specific $\dot{V} \mathrm{O}_{2 \max } 0.87$ $(P<0.001$; see Fig. 1b). The average difference between measured and estimated $\dot{V} \mathrm{O}_{2 \max }$ was not significantly different from zero $\left(0.0241 \cdot \mathrm{min}^{-1}, P=0.83\right.$ and 0.28 $\mathrm{ml} \cdot \mathrm{min}^{-1} \mathrm{~kg}^{-1}, P=0.83$ ). The LOA for individual estimates of $\dot{V} \mathrm{O}_{2 \max }$ averaged $0.41 \mathrm{l} \cdot \mathrm{min}^{-1}$ or $5.3 \mathrm{ml} \cdot \mathrm{min}^{-1} \cdot \mathrm{kg}^{-1}$, corresponding to about $8.7 \%$ (see Fig. $2 \mathrm{a}, \mathrm{b}$ ). The magnitude of the differences between measured and estimated $\dot{V} \mathrm{O}_{2 \max }$ was not dependent on the actual level of $\dot{V} \mathrm{O}_{2 \max }$, confirming the homoscedastic nature of the data. Replacement of measured $\mathrm{HR}_{\max }$ with its age-predicted match in the $\dot{V} \mathrm{O}_{2 \max }$ calculation resulted in larger differences between measured and estimated $\dot{V} \mathrm{O}_{2 \max }$. LOA increased to $\pm 0.721 \cdot \mathrm{min}^{-1}$, or $9.2 \mathrm{ml} \cdot \mathrm{min}^{-1} \cdot \mathrm{kg}^{-1}$, which corresponds to about $15 \%$ (see Fig. 2b). Moreover, statistically significant correlations were also found between $\mathrm{BM} \cdot \mathrm{HR}_{\text {max }} \cdot \mathrm{HR}_{\text {rest }}{ }^{-1}$ and $\dot{V} \mathrm{O}_{2 \max }(r=0.92 ; P<0.001)$ and between $\mathrm{HR}_{\max } \cdot \mathrm{HR}_{\text {rest }}{ }^{-1}$ and mass-specific $\dot{V} \mathrm{O}_{2 \max }$ $(r=0.86 ; P<0.001)$.

\section{Discussion}

By elaborating upon the Fick principle we developed an equation that predicts a relationship between the 
Fig. 1a, b a Scatter plot between estimated and measured maximal oxygen uptake $\left(1 \cdot \mathrm{min}^{-1}\right)$, b Scatter plot between estimated and measured mass-specific maximal oxygen uptake $\left(\mathrm{ml} \cdot \mathrm{min}^{-1} \cdot \mathrm{kg}^{-1}\right)$. The solid lines depicted are the least-squares derived best-fitting lines
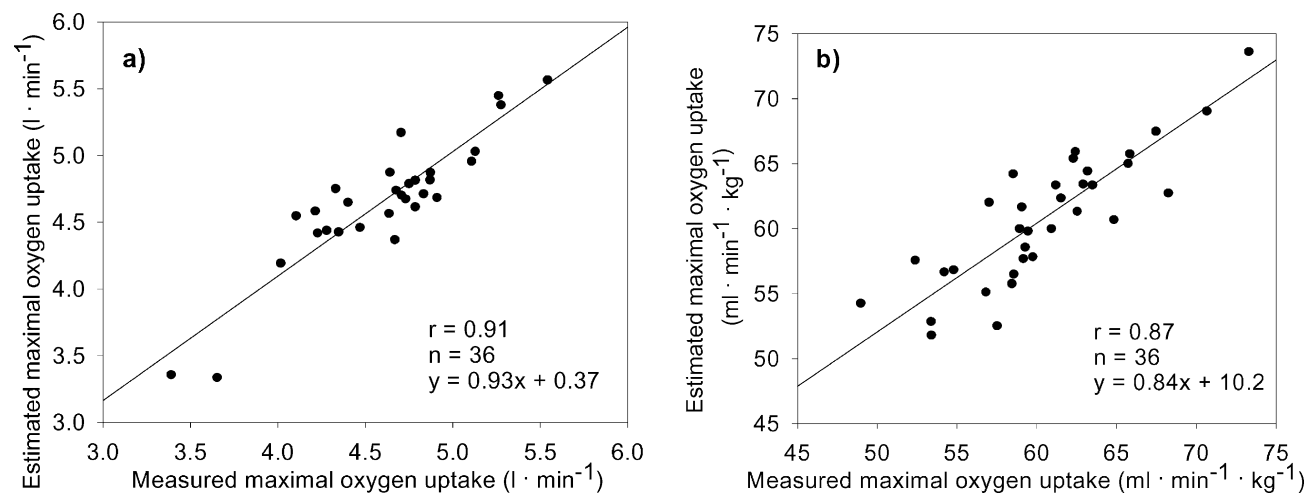

$\mathrm{HR}_{\text {max }}$-to- $\mathrm{HR}_{\text {rest }}$ ratio and mass-specific $\dot{V} \mathrm{O}_{2 \max }$. Experimental testing of ten well-trained men demonstrated that the proportionality factor applied in the conversion of $\mathrm{HR}_{\max } \cdot \mathrm{HR}_{\text {rest }}{ }^{-1}$ to $\dot{V} \mathrm{O}_{2 \max }$ was 15.26 $(0.72) \mathrm{ml} \cdot \mathrm{min}^{-1} \cdot \mathrm{kg}^{-1}$, a value which is not significantly different from the theoretically assumed value of $15.0 \mathrm{ml} \cdot \mathrm{min}^{-1} \cdot \mathrm{kg}^{-1}$. Subsequent testing of 36 trained men demonstrated that individual values for mass-specific $\dot{V} \mathrm{O}_{2 \max }$ (range $49-73 \mathrm{ml} \cdot \mathrm{min}^{-1} \cdot \mathrm{kg}^{-1}$ ) could be obtained with a SEE of $2.72 \mathrm{ml} \cdot \mathrm{min}^{-1} \cdot \mathrm{kg}^{-1}$, or $\sim 4.5 \%$. This yields a $95 \%$ confidence interval (LOA) for individual estimates of mass-specific $\dot{V} \mathrm{O}_{2 \max }$ of about $8.7 \%$.

In order to evaluate the relative merit of the above method for estimation of $\dot{V} \mathrm{O}_{2 \max }$ we have compared its SEE value with data from some other indirect tests. The Åstrand-Ryhming nomogram test from 1954, which was based upon cycle ergometer testing of 27 male and 31 female subjects, reported SEE values of $7-15 \%$. Fox's (1973) cycle ergometer study which comprised of 87 young men reported SEE to be $6-11 \%$. Kline et al. (1987) tested middle-aged men $(n=83)$ and women $(n=86)$ using a walking test in combination with anthropometry and arrived at SEE $\sim 10 \%$. Andersen (1995) used a maximal exercise protocol to predict $\dot{V} \mathrm{O}_{2 \text { max }}$ and found SEE to be $\sim 8 \%$. In comparison with these tests the Heart Rate Ratio Method may offer superior accuracy, although attention should be paid to the possible significance of its being based upon a relatively homogenous study group ("well-trained men").

It should be noticed that the regression lines of Fig. 1 cross the line of identity. The slopes of both regression lines are not significantly different from $1(P<0.001)$.
The point at which the regression line intersects the $y$ axis is significantly different from 0 in Fig. $1 \mathrm{~b}(P=0.04)$ but not in Fig. 1a $(P=0.25)$.

Age-predicted versus experimentally determined $\mathrm{HR}_{\max }$

Instead of experimentally determining $\mathrm{HR}_{\max }$ as in the above version of the test, $\mathrm{HR}_{\max }$ may also be predicted from the person's age. Use of a theoretical $H_{R_{\max }}$ value rather than an experimental one would facilitate the accomplishment of the test and potentially increase its applicability to groups of individuals where maximal effort may be unwarranted, such as patients or elderly individuals. The accuracy of the $\dot{V} \mathrm{O}_{2 \max }$ estimation was significantly less when age-predicted $\mathrm{HR}_{\max }$ values replaced the experimental ones in the formula (SEE 7.8\% versus $4.5 \%$ of the average $\dot{V} \mathrm{O}_{2 \max }$ ). Thus, the convenience obtained from not having to expose the individual to maximal exercise had a price. It is of note, however, that even with age-predicted $\mathrm{HR}_{\max }$ values SEE was still comparable with other indirect tests. It may therefore be of interest to further examine its applicability to individuals of different age and training levels.

\section{Standardization of measurement conditions}

It should be noted that the $\mathrm{SV}_{\max }$-to- $\mathrm{SV}_{\text {rest }}$ ratio is about 1.3 when measured in the supine position (as presumed in the calculation of the proportionality factor), whereas
Fig. 2a, b Limits of agreement (Bland and Altman 1986) for measured versus estimated maximal oxygen uptake using the Heart Rate Ratio Method. a $\mathrm{HR}_{\text {max }}$ is experimentally established as opposed to the age-predicted value (Tanaka et al. 2001) used in b. Upper and lower limit of agreement are indicated with solid lines while the mean difference is indicated by a dashed line
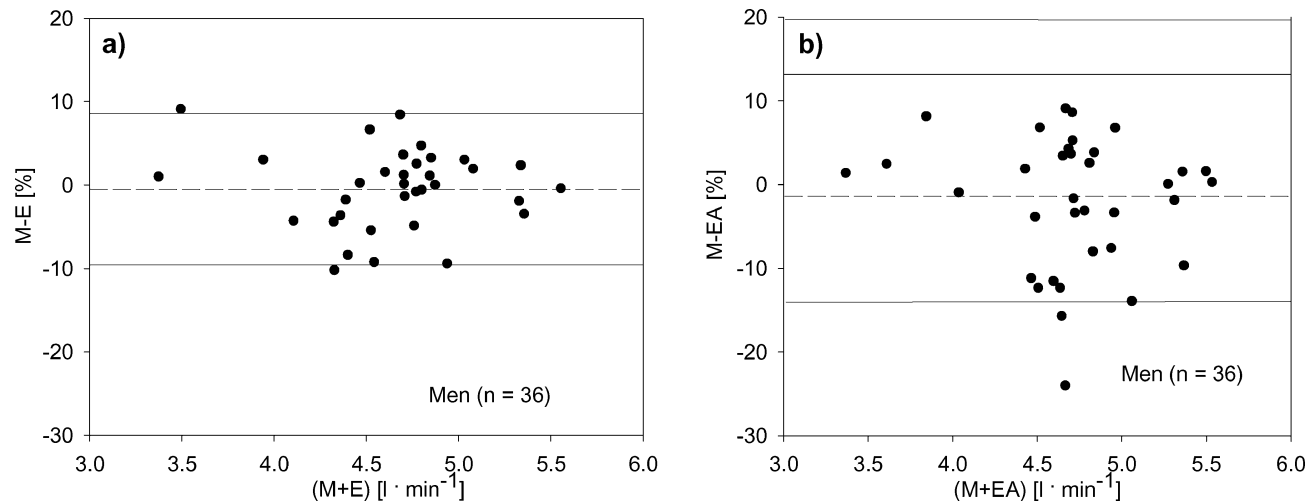
the corresponding value for the standing position would be 1.82 (Chapman et al. 1960). This emphasizes the importance of HR measurements being performed under strictly standardized conditions. Furthermore, it is important to underline that the proportionality factor between mass-specific $\dot{V} \mathrm{O}_{2 \max }$ and the $\mathrm{HR}_{\max }$-to- $\mathrm{HR}_{\text {rest }}$ ratio may vary between groups of individuals since both mass-specific resting $\dot{V} \mathrm{O}_{2 \max }$ and the max-to-rest ratios of $\mathrm{SV}$ and the arterio-venous $\mathrm{O}_{2}$ difference $\left(\mathrm{CaO}_{2}-C \bar{v} \mathrm{O}_{2}\right)$ can be influenced by factors such as age, gender and training level. Therefore valid proportionality factors should first be experimentally established before the principle of the Heart Rate Ratio Method is extended to groups other than well-trained men.

\section{Conclusion}

In a group of ten well-trained men, the proportionality factor between mass-specific $\dot{V} \mathrm{O}_{2 \max }$ and the $\mathrm{HR}_{\max }$-to$\mathrm{HR}_{\text {rest }}$ ratio was found to be $15.26 \mathrm{ml} \cdot \mathrm{min}^{-1} \cdot \mathrm{kg}^{-1}$, which was in good agreement with the theoretical value. Furthermore, when using this proportionality factor in 36 well-trained men we found that the mass-specific $\dot{V} \mathrm{O}_{2 \max }$ could be estimated from the experimentally determined $\mathrm{HR}_{\text {max }}$-to-HR $\mathrm{HR}_{\text {rest }}$ ratio with an SEE of $4.5 \%$, which appears to be superior to other common indirect tests. Moreover, when replacing the experimentally determined $\mathrm{HR}_{\max }$ with an age-predicted one, the mass-specific $\dot{V} \mathrm{O}_{2 \max }$ could be estimated by the Heart Rate Ratio Method with an SEE of $7.8 \%$. The results indicate that the principle of this test may provide a simple and useful tool for $\dot{V} \mathrm{O}_{2 \max }$ estimation.

Acknowledgement We are grateful to Dr. L. Bruce Gladden for constructive help in the preparation of the manuscript.

\section{Appendix}

Derivation of an equation for a relationship between $\dot{V} \mathrm{O}_{2 \max }$ and the ratio between $\mathrm{HR}_{\max }$ and $\mathrm{HR}_{\text {rest }}$

According to the Fick principle, $\dot{V} \mathrm{O}_{2 \max }$ may be expressed as the product of cardiac output $(\dot{Q})$ and the arterio-venous $\mathrm{O}_{2}$ difference $\left(\mathrm{CaO}_{2}-C \bar{v} \mathrm{O}_{2}\right)$.

$\dot{V} \mathrm{O}_{2}=\dot{Q} \cdot\left(C_{\mathrm{a}} \mathrm{O}_{2}-C \bar{v} \mathrm{O}_{2}\right)$

Thus, since $\bar{Q}$ is the product of HR and stroke volume (SV), $\dot{V} \mathrm{O}_{2 \max }$ can be expressed as:

$\dot{V} \mathrm{O}_{2}=\mathrm{HR} \cdot \mathrm{SV} \cdot\left(C_{\mathrm{a}} \mathrm{O}_{2}-C \bar{v} \mathrm{O}_{2}\right)$

When applied to rest $\dot{V} \mathrm{O}_{2 \max }$ can be expressed as:

$\dot{V} \mathrm{O}_{2 \text { rest }}=\mathrm{HR}_{\text {rest }} \cdot \mathrm{SV}_{\text {rest }} \cdot\left(\mathrm{CaO}_{2}-C \bar{v} \mathrm{O}_{2}\right)_{\text {rest }}$

implying that:
$\frac{\dot{V} \mathrm{O}_{2 \text { rest }}}{\mathrm{HR}_{\text {rest }} \cdot \mathrm{SV}_{\text {rest }} \cdot\left(C \mathrm{aO}_{2}-C \bar{v} \mathrm{O}_{2}\right)_{\text {rest }}}=1$

During maximal exercise the Fick equation reads:

$\dot{V} \mathrm{O}_{2 \max }=\mathrm{HR}_{\max } \cdot \mathrm{SV}_{\max } \cdot\left(\mathrm{CaO}_{2}-C \bar{v} \mathrm{O}_{2}\right)_{\max }$

By multiplying the right side of Eq. 5 with 1 in the form of Eq. 4 it follows that:

$\dot{V} \mathrm{O}_{2 \max }=\frac{\mathrm{HR}_{\max } \cdot \mathrm{SV}_{\max } \cdot\left(C \mathrm{CO}_{2}-C \bar{v} \mathrm{O}_{2}\right)_{\max }}{\mathrm{HR}_{\max } \cdot \mathrm{SV}_{\max } \cdot\left(C \mathrm{aO}_{2}-C \bar{v} \mathrm{O}_{2}\right)_{\text {rest }}} \cdot \dot{V} \mathrm{O}_{2 \text { rest }}$

or

$$
\begin{aligned}
\dot{V} \mathrm{O}_{2 \max }= & \left(\frac{\mathrm{HR}_{\text {max }}}{\mathrm{HR}_{\text {rest }}}\right) \cdot\left(\frac{\mathrm{SV}_{\text {max }}}{\mathrm{SV}_{\text {rest }}}\right) \cdot\left(\frac{\left(C \mathrm{CO}_{2}-C \bar{v} \mathrm{O}_{2}\right)_{\max }}{\left(C \mathrm{COO}_{2}-C \bar{v} \mathrm{O}_{2}\right)_{\text {rest }}}\right) \\
& \times \dot{V} \mathrm{O}_{2 \text { rest }}
\end{aligned}
$$

This implies that $\dot{V} \mathrm{O}_{2 \max }$ may be calculated as the product of $\dot{V} \mathrm{O}_{2 \max }$ and the ratios of maximal versus resting values of, respectively, HR, SV, and $\left(\mathrm{CaO}_{2}-C \bar{v} \mathrm{O}_{2}\right)$.

$\dot{V} \mathrm{O}_{2 \text { rest }}$ is dependent on and increases with the individual's body mass. Åstrand and Rodahl (1986) suggest that, relative to body mass (BM), resting $\dot{V} \mathrm{O}_{2}$ equals about $3.5 \mathrm{ml} \cdot \mathrm{min}^{-1} \cdot \mathrm{kg}^{-1}$ (one MET), but slightly lower values were reported by McCann and Adams (2002) (3.3 for men and 3.1 for women, respectively). As a compromise we chose $3.4 \mathrm{ml} \cdot \mathrm{min}^{-1} \cdot \mathrm{kg}^{-1}$ to represent the massspecific resting $\dot{V} \mathrm{O}_{2 \max }$. Accordingly, $V \mathrm{O}_{2 \text { rest }}\left(\mathrm{ml} \cdot \mathrm{min}^{-1}\right)$ may be expressed as $3.4 \mathrm{ml} \cdot \mathrm{min}^{-1} \cdot \mathrm{kg}^{-1}$ times $\mathrm{BM}$ in $\mathrm{kg}$.

$$
\begin{aligned}
\dot{V} \mathrm{O}_{2 \max }= & \left(\frac{\mathrm{HR}_{\max }}{\mathrm{HR}_{\text {rest }}}\right) \cdot\left(\frac{\mathrm{SV}_{\text {max }}}{\mathrm{SV}_{\text {rest }}}\right) \cdot\left(\frac{\left(\mathrm{CaO}_{2}-C \bar{v} \mathrm{O}_{2}\right)_{\max }}{\left(C \mathrm{CO}_{2}-C \bar{v} \mathrm{O}_{2}\right)_{\text {rest }}}\right) \\
& \times \mathrm{BM} \cdot 3.4 \mathrm{ml} \cdot \mathrm{min}^{-1} \cdot \mathrm{kg}^{-1}
\end{aligned}
$$

From a test perspective only the $\mathrm{HR}_{\max }$-to- $\mathrm{HR}_{\text {rest }}$ ratio is readily obtainable. The other two ratios in the equation involve complicated measurements, in fact more complicated than the measurement of $\dot{V} \mathrm{O}_{2}$ itself. Equation 8 suggests, however, that if the max-to-rest ratios of $\mathrm{SV}$ and $\left(\mathrm{CaO}_{2}-\mathrm{C} \bar{v} \mathrm{O}_{2}\right)$ were approximately constant across individuals, $\dot{V} \mathrm{O}_{2 \max }$ per $\mathrm{kg} \mathrm{BM}$ may be estimated by experimentally determining the $\mathrm{HR}_{\max }$-to$\mathrm{HR}_{\text {rest }}$ ratio, and multiplying this ratio with these constants and $3.4 \mathrm{ml} \cdot \mathrm{min}^{-1} \cdot \mathrm{kg}^{-1}$. Nottin et al. (2002) and Chapman et al. (1960) reported the average $\mathrm{SV}_{\text {max }} \cdot \mathrm{SV}_{\text {rest }}{ }^{-1}$ to be 1.28 and 1.29 , respectively, in men, when measured in the supine position. Thus, according to the studies mentioned it appears that $\mathrm{SV}_{\text {max }} \cdot \mathrm{SV}_{\text {rest }}{ }^{-1}$ may be replaced by a dimensionless value of approximately 1.3 .

The arterio-venous oxygen difference increases from rest to maximal exercise. Chapman et al. (1960) found the average ratio between maximal and resting 
$\left(\mathrm{CaO}_{2}-\mathrm{C} \bar{v} \mathrm{O}_{2}\right)$ to be 3.4 in men. We therefore replaced $\left(\mathrm{CaO}_{2}-C \bar{v} \mathrm{O}_{2}\right)_{\max } \cdot\left(\mathrm{CaO}_{2}-C \bar{v} \mathrm{O}_{2}\right)$ rest $^{-1}$ in Eq. 8 with 3.4. Altogether, data from the literature suggest that Eq. 8 may be simplified to the approximation:

$$
\begin{aligned}
\dot{V} \mathrm{O}_{2 \max } & =\left(1.3 \cdot 3.4 \cdot \mathrm{ml} \cdot \min ^{-1} \cdot \mathrm{kg}^{-1}\right) \cdot \mathrm{BM}(\mathrm{kg}) \cdot \frac{\mathrm{HR}_{\max }}{\mathrm{HR}_{\text {rest }}} \\
& =15.0 \mathrm{ml} \cdot \mathrm{min}^{-1} \cdot \mathrm{BM}(\mathrm{kg}) \cdot \frac{\mathrm{HR}_{\max }}{\mathrm{HR}_{\text {rest }}}, \text { or }
\end{aligned}
$$

Mass-specific $\dot{V} \mathrm{O}_{2 \max }=\left(15.0 \mathrm{ml} \cdot \mathrm{min}^{-1} \cdot \mathrm{kg}^{-1}\right) \frac{\mathrm{HR}_{\max }}{\mathrm{HR}_{\text {rest }}}$

\section{References}

Andersen LB (1995) A maximal cycle exercise protocol to predict maximal oxygen uptake. Scand J Med Sci Sports 5:143-146

Åstrand P-O, Rodahl K (1986) Textbook of work physiology. McGraw-Hill, New York, pp 362, 368

Åstrand P-O, Ryhming I (1954) A nomogram for calculation of aerobic capacity (physical fitness) from pulse rate during submaximal work. J App Physiol 7:218-221
Bland MB, Altman DG (1986) Statistical methods for assessing agreement between two methods of clinical measurement. Lancet 1:307-310

Blomqvist CG, Saltin B (1983) Cardiovascular adaptations to physical training. Annu Rev Physiol 45:169-189

Chapman CB, Fisher NJ, Sproule BJ (1960) Behavior of stroke volume at rest and during exercise in human beings. J Clin Invest 38:1208-1213

Fox EL (1973) A simple, accurate technique for predicting maximal aerobic power. J Appl Physiol 35:914-916

Howley ET, Bassett DR, Welch HG (1995) Criteria for maximal oxygen uptake: review and commentary. Med Sci Sports Exerc 27:1292-1301

Katona PG, McLean M, Dighton DH, Guz A (1982) Sympathetic and parasympathetic cardiac control in athletes and nonathletes at rest. J Appl Physiol 52:1652-1657

Kline GM, Porcari JP, Hintermeister R, Freedson PS, Ward A, McCarron RF, Ross J, Rippe JM (1987) Estimation of $\dot{V} \mathrm{O}_{2 \max }$ from a one-mile track walk, gender, age, and body weight. Med Sci Sports Exerc 19:253-259

McCann DJ, Adams WC (2002) A theory for normalizing resting $\dot{V} \mathrm{O}_{2 \max }$. Med Sci Sports Exerc 34:1382-1390

Nottin S, Vinet A, Stecken F, Nguyen LD, Ounissi F, Lecoq AM, Obert P (2002) Central and peripheral cardiovascular adaptations during a maximal cycle exercise in boys and men. Med Sci Sports Exerc 34:56-63

Tanaka H, Monahan KD, Seals DR (2001) Age-predicted maximal heart rate revisited. J Am Coll Cardiol 37:153-156 